\title{
Sulforaphane Augments Glutathione and Influences Brain Metabolites in Human Subjects: A Clinical Pilot Study
}

\author{
Thomas W. Sedlak $^{\mathrm{a}}$ Leslie G. Nucifora ${ }^{\mathrm{a}}$ Minori Koga $^{\mathrm{a}}$ Lindsay S. Shaffer $^{\mathrm{a}}$
}

Cecilia Higgs $^{\text {a }}$ Teppei Tanaka ${ }^{a}$ Anna M. Wang ${ }^{b}$ Jennifer M. Coughlin ${ }^{a}$

Peter B. Barker ${ }^{b}$ Jed W. Fahey ${ }^{c} \quad$ Akira Sawa $^{a}$

a Department of Psychiatry and Behavioral Sciences, The Johns Hopkins University School of Medicine, Baltimore, MD, USA; ${ }^{b}$ Department of Radiology and Radiological Sciences, The Johns Hopkins University School of Medicine, Baltimore, MD, USA; ' ${ }^{2}$ epartment of Clinical Pharmacology, The Johns Hopkins University School of Medicine, Baltimore, MD, USA

\section{Keywords}

Sulforaphane · Glutathione · Oxidative stress

\begin{abstract}
Schizophrenia and other neuropsychiatric disorders await mechanism-associated interventions. Excess oxidative stress is increasingly appreciated to participate in the pathophysiology of brain disorders, and decreases in the major antioxidant, glutathione (GSH), have been reported in multiple studies. Technical cautions regarding the estimation of oxidative stress-related changes in the brain via imaging techniques have led investigators to explore peripheral GSH as a possible pathological signature of oxidative stress-associated brain changes. In a preclinical model of GSH deficiency, we found a correlation between whole brain and peripheral GSH levels. We found that the naturally occurring isothiocyanate sulforaphane increased blood GSH levels in healthy human subjects following 7 days of daily oral administration. In parallel, we explored the potential influence of sulforaphane on brain GSH levels in the anterior cingulate cortex, hippocampus, and thalamus via 7-T magnetic resonance
\end{abstract}

spectroscopy. A significant positive correlation between blood and thalamic GSH post- and pre-sulforaphane treatment ratios was observed, in addition to a consistent increase in brain GSH levels in response to treatment. This clinical pilot study suggests the value of exploring relationships between peripheral GSH and clinical/neuropsychological measures, as well as the influences sulforaphane has on functional measures that are altered in neuropsychiatric disorders.

C 2018 S. Karger AG, Basel

\section{Introduction}

Oxidative stress underlies the pathophysiology of multiple human disorders, ranging from cardiovascular syndromes and diabetes to neurodegenerative conditions such as Alzheimer and Parkinson disease [1-5]. Furthermore, recent studies have suggested that oxidative stress also plays a role in neuropsychiatric conditions such as schizophrenia (SZ) [6-9].

\section{KARGER}

(c) 2018 S. Karger AG, Basel

E-Mail karger@karger.com

www.karger.com/mnp
Thomas W. Sedlak or Akira Sawa

Department of Psychiatry and Behavioral Sciences

The Johns Hopkins University School of Medicine

Baltimore, MD 21287 (USA)

E-Mail tsedlak@jhmi.edu or asawa1@jhmi.edu 
Glutathione (GSH) is one of the most important regulators of oxidative stress and redox balance. This antioxidant tripeptide exists at low millimolar intracellular levels and is directly utilized by over 20 enzymes to exert its antioxidant and cytoprotective effects. Involvement of GSH in pathological conditions has been reported for many diseases [10-13].

An obstacle to the study and treatment of brain disorders is access to biological specimens, which are more readily available for diseases of the periphery. Thus, many studies rely upon more accessible blood and cerebral spinal fluid samples to characterize the molecular underpinnings of neuropsychiatric conditions [14-23]. Although there is variability between subjects, multiple studies have reported a significant reduction of GSH in SZ in peripherally accessible tissues and fluids, such as blood $[6,18$, 19, 24-29].

However, the molecular disposition of GSH in the brain associated with $\mathrm{SZ}$ is unclear. In vivo magnetic resonance spectroscopy (MRS) is an analytical technique used to measure levels of brain metabolites [30]. Successful application of MRS has shown alterations in brain glutamate (Glu) and $\gamma$-aminobutyric acid (GABA) levels in SZ patients [31-34]. In contrast, the data for GSH have been less consistent $[19,35,36]$. The limited sensitivity of 3-T MRS in detecting GSH levels may be the underlying source of this inconsistency, and studies with 7-T MRS should improve detection and yield more consistent results. Therefore, at present we should be cautious about interpreting MRS-based measures of GSH. The current MRS methodology may not be sensitive enough to detect subtle but critical changes in association with pathological alterations. As a result, many investigators are exploring the potential utility of peripheral GSH as a possible signature of oxidative stress-associated brain changes.

Sulforaphane is a natural phytochemical compound abundant in the seeds and sprouts of cruciferous plants such as broccoli. It has shown promise in preclinical models of traumatic brain and spinal cord injury $[37,38]$. Sulforaphane activates the transcription factor NF-E2related factor 2 ( Nrf2) via its ability to bind to and disassociate its cytosolic inhibitor kelch-like ECH-associated protein 1 (KEAP1) [39, 40]. Thus, sulforaphane is expected to facilitate proper redox balance and protection against oxidative stress [41]. Because of its presence in consumable food, sulforaphane is an attractive candidate for further human study. Indeed, its potential utility has been demonstrated in the treatment of asthma, air pollution injury, benign prostate hyperplasia, UV-induced erythema, diabetes, the control of Helicobacter pylori (a stomach carcinogen), and potentially in the prevention of a number of different cancers [42-44]. Furthermore, recent reports have suggested that administration of sulforaphane leads to beneficial outcomes of human brain disorders such as autism and SZ [45-47]. Nevertheless, it remains elusive how sulforaphane may mechanistically interface with the pathogenesis of neuropsychiatric conditions.

We hypothesized that the administration of sulforaphane to human subjects could augment blood and brain GSH levels, and that peripheral blood GSH levels may reflect the oxidative stress- and redox-associated physiology and pathophysiology in the brain. Given that sulforaphane may be a candidate treatment, studying the influence of sulforaphane on GSH may be the first step in defining markers for predicting beneficial effects.

\section{Methods}

\section{Mouse Model}

Excitatory amino acid carrier-1 knockout (Eaac1 KO) [48] and wild-type (WT) mice, both having a CD1 background, were used in this study and housed in a controlled facility $\left(23 \pm 1^{\circ} \mathrm{C} ; 50 \pm 5 \%\right.$ humidity; light and dark cycles started at 7 a.m. and 7 p.m., respectively) with free access to food and water. GSH levels were quantified in whole brain from 3-month-old male mice (Eaacl KO mice, $n=4$; WT mice, $n=5$ ). We utilized male animals as rodent GSH enzyme levels fluctuate up to $50 \%$ during estrus [49]. Threemonth-old animals are free from the age-dependent decline in GSH levels observed in rodents over 1 year of age [50].

\section{Broccoli Sprout Extract (Sulforaphane)}

The broccoli sprout extract used in this study is a highly standardized formulation of sulforaphane $[51,52]$. The extract was standardized to $100 \mu \mathrm{mol}$ sulforaphane in the form of 2 gel capsules per day over 7 consecutive days, as described previously [ 45 , 53-58]. The dose of $100 \mu \mathrm{mol}$ sulforaphane and the 7-day treatment duration were determined empirically from previous studies, including a trial demonstrating induction of antioxidant enzymes in nasal lavage cells of human subjects [59] and improved excretion of air pollutants [56]. Our formulation of sulforaphane is $80 \%$ bioavailable [58], reaches peak plasma levels $1 \mathrm{~h}$ after oral ingestion, declines with first-order kinetics, and is actively excreted in urine $(60 \%$ at $8 \mathrm{~h})[58,60]$.

\section{Human Study Participants}

Nine healthy volunteers ( 5 male and 4 female) were recruited at the Johns Hopkins Schizophrenia Center, Baltimore, MD, USA. The demographic information is presented in Table 1. GSH levels are similar in men and women, though they start to decline over 60 years of age [61]. The present study included younger participants (aged 21-26 years, with 1 participant aged 56 years). Subjects were excluded if they had a personal or immediate family history of severe psychiatric illness, a history of a recent nosocomial infection, chronic neurological disorders, a traumatic head injury re- 
Table 1. Clinical and demographic characteristics

$\begin{array}{lc}\text { Sex, } n(\%) & \\ \text { Male } & 5(56) \\ \text { Female } & 4(44) \\ \text { Mean age } \pm \text { SD, years } & 27.8 \pm 10.67 \\ \text { Race/ethnicity, } n(\%) & \\ \text { Caucasian } & 2(22) \\ \text { African American } & 3(34) \\ \text { Asian } & 2(22) \\ \text { Other } & 2(22) \\ \text { Education, } n(\%) & \\ \text { Advanced degree } & 5(56) \\ \text { Undergraduate } & 4(44) \\ \text { Smoking, } n(\%) & \\ \text { Smoker } & 0(0) \\ \text { Nonsmoker } & 9(100)\end{array}$

sulting in loss of consciousness, or active substance abuse. We excluded tobacco smokers from this study, as smoking is a known inducer of oxidative stress $[62,63]$. Patients with contraindications to MRI scanning, such as dependence on benzodiazepine medication, prohibitive claustrophobia, metallic implants or prosthetics, pacemakers, or any medical conditions that would constitute a safety risk to the participant (e.g., middle ear disorder), were also excluded.

\section{Clinical Study Design}

The participants completed two visits, scheduled 7 days (1 week) apart. The participants were given $100 \mu \mathrm{mol}$ sulforaphane as standardized broccoli sprout extract in the form of 2 gel capsules, and instructed to ingest the extract each morning for 1 week. The research coordinators contacted the participants by telephone to provide daily reminders on taking the extract. Urine and blood specimens were collected prior to the first dose of broccoli sprout extract and within $4 \mathrm{~h}$ of the final dose. MRS scans were performed prior to the first dose and within $4 \mathrm{~h}$ of ingesting the final dose. The participants completed a log of the dates and times of taking the extract and documented any potential discomforts or ailments they experienced during the study. Three participants indicated mild-to-moderate nausea or abdominal pain when the extract was taken on an empty stomach. The study design is summarized in online supplementary Figure 1 (for all online suppl. material, see www.karger.com/doi/10.1159/000487639).

\section{Measurement of GSH Levels in Blood and Brain Tissue (Murine and Human)}

Total GSH (the sum of GSH and glutathione disulfide [GSSG]) was measured in human blood cells using modifications of Tietze's method [64]. We refer to "total GSH" simply as "GSH." We have quantified GSH and oxidative stress in multiple studies using these methodologies $[18,65,66]$. Nonmonocytic blood cells were resuspended in a buffer containing $200 \mathrm{mM} 2$-(N-morpholino)ethanesulfonic acid and $1 \mathrm{mM}$ EDTA (ethylenediaminetetraacetic acid) and sonicated. The lysed cell suspension was then spun at $10,000 \mathrm{~g}$ for $15 \mathrm{~min}$ at $4{ }^{\circ} \mathrm{C}$. The resultant supernatant was deproteinized by adding $50 \% \mathrm{v} / \mathrm{v}$ of freshly prepared $10 \%$ metaphosphoric acid followed by a 5 -min incubation at room temperature. The deproteinized samples were then spun at 2,000 $\mathrm{g}$ for $2 \mathrm{~min}$, and the supernatant was stored at $-20^{\circ} \mathrm{C}$ until assaying. The kinetic assay was performed by adding $5 \mu \mathrm{L}$ of freshly prepared $4 \mathrm{M}$ triethanolamine to $100 \mu \mathrm{L}$ of metaphosphoric acid-treated cell lysates. GSH was then measured using a kit (Cayman Chemical Company; 703002) in strict accordance with the manufacturer's instructions. The rate of increase in absorbance at $415 \mathrm{~nm}$, which measures the reduction of $5,5^{\prime}$-dithiobis(2-nitrobenzoic acid) by GSH, reflects the total GSH content. The kinetic assay was allowed to run for $20 \mathrm{~min}$, with data collected at every 1-min interval. The concentration of total GSH in plasma was reported as $\mathrm{nmol} / \mathrm{mL}$. A standard curve from 0 to $16 \mathrm{nmol} / \mathrm{mL}$ was used to calibrate the assay. Each reported GSH value was determined using the average of 2 independent measurements.

\section{7-T Magnetic Resonance Spectroscopy}

All participants were scanned using a 7-T scanner (Philips Achieva; Philips, Best, The Netherlands) equipped with a 32-channel head coil (Nova Medical, Wilmington, MA, USA). 3D T1weighted images were acquired using a magnetization-prepared rapid acquisition with gradient echo sequence $(\mathrm{FOV}=220 \times 220 \times$ $180 \mathrm{~mm})$. Spectra were recorded from the anterior cingulate cortex (ACC; $30 \times 30 \times 30 \mathrm{~mm}$ ), left hippocampus (HP; $35 \times 15 \times 15 \mathrm{~mm}$ ), and bilateral thalamus (THAL; $20 \times 30 \times 15 \mathrm{~mm}$ ) using a stimulated echo acquisition mode sequence $(\mathrm{TE} / \mathrm{TM} / \mathrm{TR}=14 / 33 / 3,000$ $\mathrm{ms}$, NEX = 128), except for 2 participants where spectra were only recorded from the ACC with a voxel size of $38 \times 30 \times 30 \mathrm{~mm}$ (online suppl. Fig. 2).

Not all the remaining participants had MRS data acquired for all three brain regions. VAPOR (variable power and optimized relaxation delays) water suppression was used to minimize the dominant water signal [67]. In addition, a reference scan without water suppression was also acquired from each voxel (NEX = 16). Spectra were analyzed with the LCModel software package [68] and a basis set was simulated from the VeSPA project [69]. Metabolite concentrations were normalized using the unsuppressed water signal as the reference. Fitting errors were assessed by CRLBs (Cramér-Rao lower bounds). Metabolite concentrations were only included in further statistical analyses when the corresponding CRLB values were below $20 \%$.

The goal of our study was to determine changes in brain GSH levels upon sulforaphane treatment, possibly in correlation with levels of blood GSH; therefore GSH was our primary outcome measure. GABA, glutamine (Gln), Glu, and N-acetylaspartate (NAA) served as secondary outcome measures. Differences between pre- and posttreatment measurements in concentrations of GABA, Gln, Glu, GSH, and NAA were compared using a paired $t$ test.

\section{Analysis and Statistics}

Statistical analyses were performed using R version 3.3.0 for Windows. The correlative relationship between blood GSH levels and brain metabolite levels measured by MRS was calculated using the pre- and post-sulforaphane blood GSH ratios and metabolite ratios. The blood GSH ratios were nonparametric as determined by the Shapiro-Wilk normality test; therefore, Spearman's correlation coefficient was used to determine the relationship between blood GSH and brain MRS data. For nonparametric data, the 


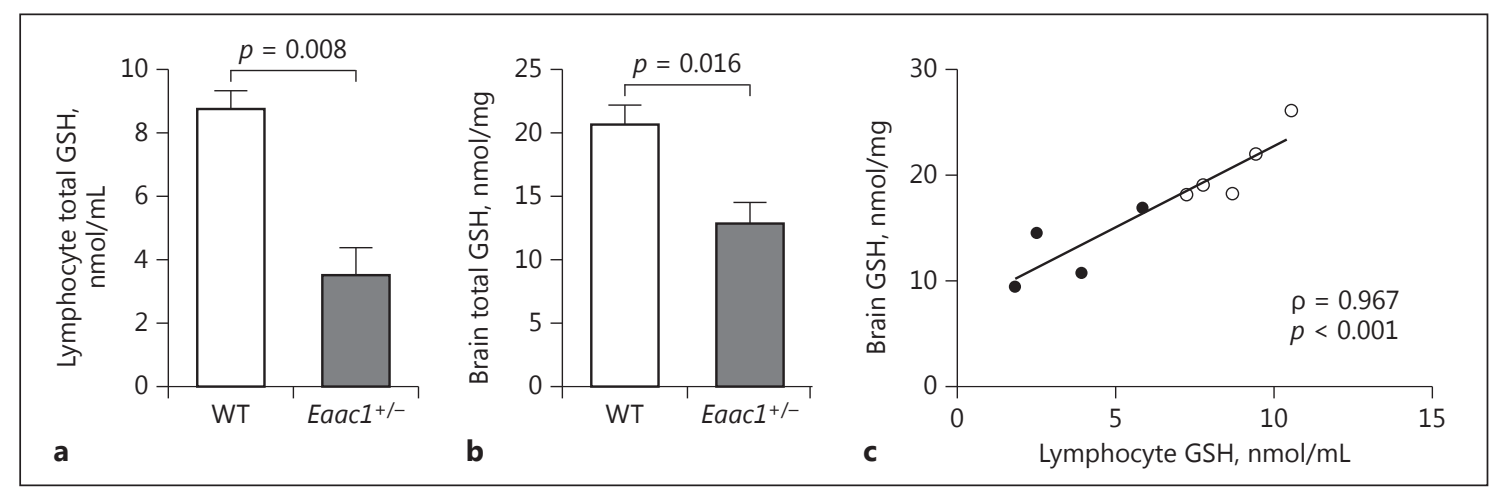

Fig. 1. Measurement of glutathione (GSH) levels in blood cells and brain tissue in wild-type (WT) and Eaac1 knockout (+/-) mice. a The levels of total GSH in lymphocytes were significantly reduced in the 3-month-old male Eaac1+/- mice $(n=4)$ compared with the WT littermates $(n=5)$. b The levels of total GSH in whole brain were significantly reduced in the Eaac1+/- mice compared with the WT littermates. c The levels of total GSH in the lymphocytes and those in the brain were different between individual animals (white circles, WT mice; black circles, Eaac1+/- mice). Nevertheless, the ratio of the level of total GSH in the lymphocytes to that in the brain was constant.
Mann-Whitney test was used to perform two group comparisons between total GSH levels in WT and Eaac1 KO mice in both lymphocytes and brain. Spearman's correlation coefficient was used to determine the relationship between total GSH levels in the brain and those in lymphocytes of mice.

Spearman's correlation analysis and a pair-wise, two-tailed $t$ test were used to determine the influence of sex on the sulforaphane response in blood GSH levels. Wilcoxon rank sum testing was used to determine whether racial categories were covariates of GSH levels in blood. Pearson's correlation analysis was used to determine the influence of age on the sulforaphane response in blood GSH levels. In order to perform a thorough analysis, a univariate and a multivariate linear regression model were used to determine the influence of race and age and of sex and race, respectively, on the sulforaphane response in THAL GSH levels. The Shapiro-Wilk test was applied to confirm normality (parametric or nonparametric). $p$ values were adjusted using the method of Benjamini and Hochberg. All data are expressed as means \pm standard deviation (SD) and an alpha of $p<0.05$.

\section{Results}

\section{Peripheral and Brain GSH Levels Observed in the Mouse Models}

We examined whether peripheral GSH levels may reflect pathophysiological changes in brain GSH levels in animal models. We initially utilized a mouse model system to study the effects of GSH deficiency in blood and brain within the controlled genetic and environmental setting afforded by these models. Since studying the influence of sulforaphane administration on GSH levels was our main interest and human studies typically have some level of genetic and environmental variability, we hoped that the mouse models could guide our human study in examining the relationship of peripheral to brain GSH levels within a controlled genetic and environmental system. We used Eaac1 KO mice, which have reduced GSH levels in the brain owing to deficient synthesis [48], although alterations in GSH in the periphery remain elusive. First, we replicated the previous finding [48] that levels of brain GSH were decreased in Eaac1 KO mice compared with WT mice (Fig. 1a). We now report that peripheral circulating lymphocytes of Eaac1 KO mice had greatly reduced GSH levels compared to WT mice $(p=0.008)$ (Fig. 1b). Importantly, brain and peripheral GSH levels were strongly correlated in both WT and KO mice ( $\rho=0.967 ; p<0.001)$ (Fig. 1c). Thus, although we need to be cautious about generalizing these observations, the measurement of peripheral GSH levels might be a potentially useful index of brain GSH levels.

\section{Increased Levels of Blood GSH in Human Subjects following Daily Administration of Sulforaphane for 7 Consecutive Days}

Pre- and post-dose urine analysis confirmed the presence of urinary sulforaphane metabolites, affirming the participants' adherence to the oral sulforaphane protocol (data not shown). Following 1-week administration of sulforaphane, the study participants demonstrated a significant augmentation of GSH in non-monocytes that include a mixture of T cells, B cells, and NK cells (Fig. 2). The GSH level was $9.22 \mathrm{nmol} / \mathrm{mL}$ before sulforaphane 


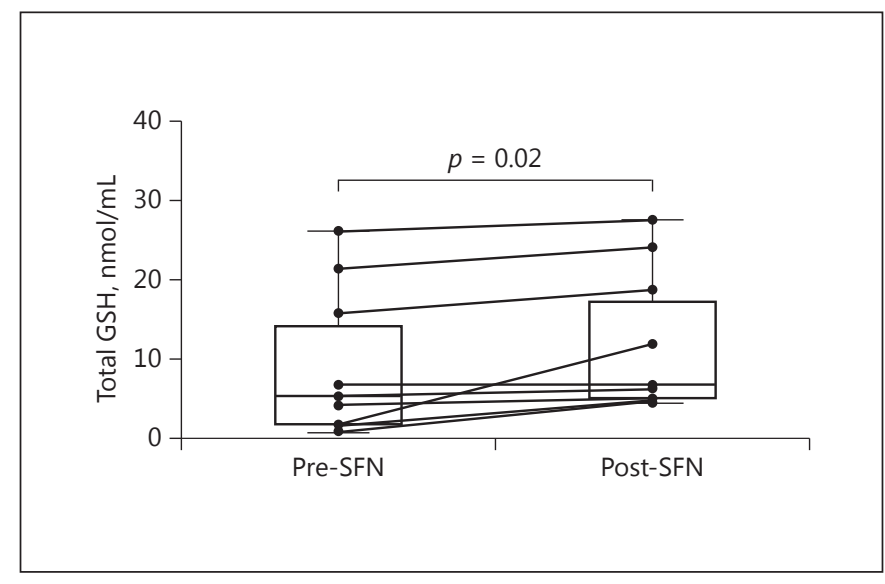

Fig. 2. Measurement of glutathione (GSH) levels in human blood cells. Cellular GSH was significantly increased following a 1-week administration of sulforaphane (SFN) (two-tailed, paired $t$ test: $p=0.02$ ).

administration and $12.2 \mathrm{nmol} / \mathrm{mL}$ following sulforaphane administration, a $32 \%$ increase. Neither the participants' age $(r=-0.1936 ; p=0.62)$ nor their sex $(\rho=0.087$; $p=0.825$ ) was found to be an explanatory covariate for the effect of sulforaphane on GSH. Race was not found to be an explanatory variable either, as demonstrated by Wilcoxon rank sum testing of the four groups $(p=0.318)$.

\section{Measuring Brain Metabolites by MRS}

In this study we obtained measurements of five metabolites (GSH, GABA, Gln, Glu, and NAA) in three different brain regions (THAL, HP, and ACC). We specifically chose these three brain regions as they underlie the key structural and functional connectivity affected in SZ [70-77]. Our primary hypothesis in the present study is that sulforaphane may affect levels of GSH in these brain regions, and may possibly be correlated with GSH levels in peripheral blood.

We identified an increase in HP GSH from $1.11 \pm 0.34$ to $1.38 \pm 0.28 \mathrm{mM}$ ( $p=0.041$; paired, two-tailed $t$ test; online supplementary Figure 2). The change in levels of GSH in the THAL and ACC did not reach significance. A representative pair-wise analysis of THAL GSH levels before and after sulforaphane administration is shown in online supplementary Figure 3. Regarding the other brain metabolites quantified for the non-primary hypothesis of the present study, the level of Gln in the THAL increased from $1.21 \pm 0.22$ to $1.49 \pm 0.26 \mathrm{mM}(p=0.017$; paired, twotailed $t$ test). Due to the limited sample size, the increase did not remain significant following post hoc correction for multiple comparisons, but the result remains suggestive when considering the small number of participants.

The sulforaphane response in brain GSH levels is not influenced by age, sex, or race, as determined by linear regression analysis. We performed a representative analysis of the GSH levels measured in the THAL because this region yielded results most significantly correlated with the biochemical measurement of GSH levels in the blood before and after sulforaphane ingestion. The respective $p$ values, for example, for the GSH levels in the THAL before and after sulforaphane administration for age, sex, and race were $0.582,0.900$, and 0.567 , respectively, in the multivariate linear regression analysis, and $p=0.406$ in the univariate analysis for race. Taken together, age, sex, and race are not covariates associated with sulforaphane response in brain GSH levels.

We observed a significantly positive correlation between GSH levels in blood and those in the THAL brain region $(\rho=0.943 ; p=0.017 ; q=0.051)$. For transparency we also report the correlative results obtained for all five metabolites measured within the three different brain regions (online suppl. Table 1). Following sulforaphane administration, the increase in blood GSH was positively correlated with GABA, Gln, Glu, and GSH in the THAL. Although these correlations were not significant following multiple comparison, they remain suggestive. Power analysis calculations suggest that a sample size of $n=50$ would yield a significant result, and this will be the focus of a future study.

\section{Discussion}

We report that a short-term administration of sulforaphane was sufficient to significantly increase peripheral GSH levels in human subjects. We found an increase in GSH in the HP, but not elsewhere in the brain regions assessed. The peripheral GSH ratio had a strong and significantly positive correlation with brain GSH levels in the THAL upon sulforaphane treatment, consistent with the results obtained from our genetically and environmentally homogeneous preclinical GSH deficiency mouse model study.

Within this study, we performed statistical analyses to verify that age, sex, and race do not influence the sulforaphane response in GSH levels in our participant population. Although GCLC GAG TNR polymorphism reportedly influences GSH levels in the European Caucasian population [78], we reported that specific genotypes may not have affected the levels in our study population 
(the group of North Americans that include African Americans) [79]. It remains elusive which genetic and/or environmental factors potentially influence the sulforaphane response in GSH levels.

As has been reported for cardiovascular and cerebrovascular diseases, longer treatment duration and/or higher dosages may be warranted. For example, in a clinical trial involving human subjects with type 2 diabetes, improvements in oxidative stress were reported with a dose of sulforaphane of $10 \mathrm{~g} /$ day $(\sim 225 \mu \mathrm{mol})$ and a duration of 4 weeks, each substantially more than in the present study [80]. This may account for the fact that we only observed suggestive changes in brain metabolites following sulforaphane treatment in the present study. Nevertheless, our short-term dosing strategy was well tolerated, which will further facilitate subsequent sulforaphane protocols in an attempt to link clinical biomarkers with patient-oriented outcomes.

Peripheral and brain GSH levels were correlated in mice when both were quantified by a standard biochemical assay. Nonetheless, it is less clear what the sulforaphane-elicited augmentation of GSH in the blood implies for the brain, at least for the present dosage and duration of sulforaphane use. Estimating GSH concentrations in the brain via MRS in human subjects has limitations or requires caution at least at present [81]. Sulforaphane likely crosses the blood-brain barrier, although its potency and necessary dosing for doing so is not yet established in humans. In rats, peripheral administration of sulforaphane can induce the anti-inflammatory $\mathrm{HO}-1$ gene in the brain, and beneficial effects have been noted on stroke, traumatic brain injury, and phencyclidine-induced hyperlocomotion $[37,82,83]$.

Outcome studies for sulforaphane interventions will benefit from connecting clinical phenotypes to objectively measured biomarkers that may reflect disease patho- physiology [47]. For example, in a submitted study, we will report that peripheral GSH levels may be correlated with cognitive functions. We thus posit the significance of exploring the possible correlations between peripheral GSH and clinical/neuropsychological measures and the influence of sulforaphane on such functional measures that are altered in neuropsychiatric disorders. The present study is a key first step toward such future studies.

\section{Acknowledgements}

This work was supported by the National Institute of Mental Health (MH-094268) Silvio O. Conte Center (A.S.), MH092443 (A.S.), MH105660 (A.S.), NS057824 (T.W.S.), and the Hilliard Fund (T.W.S.). We like to thank Drs. Koko Ishizuka and Frederick C. Nucifora Jr. for assistance with the manuscript, Ms. Yukiko Lema for editorial feedback and overall management of study participant recruitment, and Dr. Jeffrey Rothstein for providing us with the Eaac1 KO mice for the experiment.

\section{Statement of Ethics}

All animal protocols and experiments were approved by the Johns Hopkins Animal Care and Use Program and in accordance with the guidelines for the care and use of laboratory animals issued by the National Institutes of Health.

All human participants provided written informed consent. All methods and experimental protocols used in this study were approved by the Johns Hopkins University Institutional Review Board (IRB\# NA_00073385; principal investigator: T.W.S.). All experiments were performed in accordance with the guidelines and regulations established by the abovementioned IRB.

\section{Disclosure Statement}

We have no conflict of interest to declare.

\section{References}

1 Stadler K: Oxidative stress in diabetes. Adv Exp Med Biol 2012;771:272-287.

-2 De Marchi E, Baldassari F, Bononi A, Wieckowski MR, Pinton P: Oxidative stress in cardiovascular diseases and obesity: role of p66Shc and protein kinase C. Oxid Med Cell Longev 2013;2013:564961.

3 Martinez-Useros J, Li W, Cabeza-Morales M, Garcia-Foncillas J: Oxidative stress: a new target for pancreatic cancer prognosis and treatment. J Clin Med 2017;6:E29.
4 Perry G, Sayre LM, Atwood CS, Castellani RJ, Cash AD, Rottkamp CA, Smith MA: The role of iron and copper in the aetiology of neurodegenerative disorders: therapeutic implications. CNS Drugs 2002;16:339-352.

5 Dias V, Junn E, Mouradian MM: The role of oxidative stress in Parkinson's disease. J Parkinsons Dis 2013;3:461-491.

-6 Koga M, Serritella AV, Sawa A, Sedlak TW: Implications for reactive oxygen species in schizophrenia pathogenesis. Schizophr Res 2016;176:52-71.
7 Kulak A, Steullet P, Cabungcal JH, Werge T, Ingason $\mathrm{A}$, Cuenod $\mathrm{M}$, Do KQ: Redox dysregulation in the pathophysiology of schizophrenia and bipolar disorder: insights from animal models. Antioxid Redox Signal 2013; 18:1428-1443.

8 Landek-Salgado MA, Faust TE, Sawa A: Molecular substrates of schizophrenia: homeostatic signaling to connectivity. Mol Psychiatry 2016;21:10-28.

9 Owen MJ, Sawa A, Mortensen PB: Schizophrenia. Lancet 2016;388:86-97.
Sulforaphane Augments Glutathione and Influences Brain Metabolites
Mol Neuropsychiatry 2017;3:214-222 DOI: $10.1159 / 000487639$ 
10 Smeyne M, Smeyne RJ: Glutathione metabolism and Parkinson's disease. Free Radic Biol Med 2013;62:13-25.

-11 Shimizu H, Kiyohara Y, Kato I, Kitazono T, Tanizaki Y, Kubo M, Ueno H, Ibayashi S, Fujishima M, Iida M: Relationship between plasma glutathione levels and cardiovascular disease in a defined population: the Hisayama study. Stroke 2004;35:2072-2077.

-12 Johnson WM, Wilson-Delfosse AL, Mieyal JJ: Dysregulation of glutathione homeostasis in neurodegenerative diseases. Nutrients 2012; 4:1399-1440.

-13 Ballatori N, Krance SM, Notenboom S, Shi S, Tieu K, Hammond CL: Glutathione dysregulation and the etiology and progression of human diseases. Biol Chem 2009;390:191-214.

$\checkmark 14$ Coughlin JM, Hayes LN, Tanaka T, Xiao M, Yolken RH, Worley P, Leweke FM, Sawa A: Reduced superoxide dismutase-1 (SOD1) in cerebrospinal fluid of patients with early psychosis in association with clinical features. Schizophr Res 2017;183:64-69.

15 Coughlin JM, Ishizuka K, Kano SI, Edwards JA, Seifuddin FT, Shimano MA, Daley EL, Zandi PP, Leweke FM, Cascella NG, Pomper MG, Yolken RH, Sawa A: Marked reduction of soluble superoxide dismutase-1 (SOD1) in cerebrospinal fluid of patients with recentonset schizophrenia. Mol Psychiatry 2013;18: $10-11$.

16 Coughlin JM, Wang Y, Ambinder EB, Ward RE, Minn I, Vranesic M, Kim PK, Ford CN, Higgs C, Hayes LN, Schretlen DJ, Dannals RF, Kassiou M, Sawa A, Pomper MG: In vivo markers of inflammatory response in recentonset schizophrenia: a combined study using $\left[{ }^{11} \mathrm{C}\right] \mathrm{DPA}-713$ PET and analysis of CSF and plasma. Transl Psychiatry 2016;6:e777.

-17 Hayes LN, Severance EG, Leek JT, Gressitt KL, Rohleder C, Coughlin JM, Leweke FM, Yolken RH, Sawa A: Inflammatory molecular signature associated with infectious agents in psychosis. Schizophr Bull 2014;40:963-972.

18 Nucifora LG, Tanaka T, Hayes LN, Kim M, Lee BJ, Matsuda T, Nucifora FC Jr, Sedlak T, Mojtabai R, Eaton W, Sawa A: Reduction of plasma glutathione in psychosis associated with schizophrenia and bipolar disorder in translational psychiatry. Transl Psychiatry 2017;7:e1215.

-19 Do KQ, Trabesinger AH, Kirsten-Krüger M, Lauer CJ, Dydak U, Hell D, Holsboer F, Boesiger P, Cuenod M: Schizophrenia: glutathione deficit in cerebrospinal fluid and prefrontal cortex in vivo. Eur J Neurosci 2000;12: 3721-3728.

20 Wu JQ, Chen DC, Tan YL, Tan S, Wang Z, Yang F, Soares JC, Zhang XY: Association of altered $\mathrm{CuZn}$ superoxide dismutase and cognitive impairment in schizophrenia patients with tardive dyskinesia. J Psychiatr Res 2014; 58:167-174.
21 Wu Z, Zhang XY, Wang H, Tang W, Xia Y, Zhang F, Liu J, Fu Y, Hu J, Chen Y, Liu L, Chen DC, Xiu MH, Kosten TR, He J: Elevated plasma superoxide dismutase in first-episode and drug naive patients with schizophrenia: inverse association with positive symptoms. Prog Neuropsychopharmacol Biol Psychiatry 2012;36:34-38.

-22 Isgren A, Sellgren C, Ekman CJ, HolménLarsson J, Blennow K, Zetterberg H, Jakobsson J, Landén M: Markers of neuroinflammation and neuronal injury in bipolar disorder: relation to prospective clinical outcomes. Brain Behav Immun 2017;65:195-201.

23 Flatow J, Buckley P, Miller BJ: Meta-analysis of oxidative stress in schizophrenia. Biol Psychiatry 2013;74:400-409.

24 Altuntas I, Aksoy H, Coskun I, Çayköylü A, Akçay F: Erythrocyte superoxide dismutase and glutathione peroxidase activities, and malondialdehyde and reduced glutathione levels in schizophrenic patients. Clin Chem Lab Med 2000;38:1277-1281.

25 Dietrich-Muszalska A, Olas B, Glowacki R, Bald E: Oxidative/nitrative modifications of plasma proteins and thiols from patients with schizophrenia. Neuropsychobiology 2009;59: $1-7$.

26 Micó JA, Rojas-Corrales MO, Gibert-Rahola J, Parellada M, Moreno D, Fraguas D, Graell M, Gil J, Irazusta J, Castro-Fornieles J, Soutullo C, Arango C, Otero S, Navarro A, Baeza I, Martínez-Cengotitabengoa M, GonzálezPinto A: Reduced antioxidant defense in early onset first-episode psychosis: a case-control study. BMC Psychiatry 2011;11:26.

27 Raffa M, Atig F, Mhalla A, Kerkeni A, Mechri A: Decreased glutathione levels and impaired antioxidant enzyme activities in drug-naive first-episode schizophrenic patients. BMC Psychiatry 2011;11:124.

28 Raffa M, Mechri A, Othman LB, Fendri C, Gaha L, Kerkeni A: Decreased glutathione levels and antioxidant enzyme activities in untreated and treated schizophrenic patients. Prog Neuropsychopharmacol Biol Psychiatry 2009;33:1178-1183.

29 Lavoie S, Berger M, Schlögelhofer M, Schäfer MR, Rice S, Kim SW, Hesse J, McGorry PD, Smesny S, Amminger GP: Erythrocyte glutathione levels as long-term predictor of transition to psychosis. Transl Psychiatry 2017;7: e1064.

30 Wijtenburg SA, Yang S, Fischer BA, Rowland LM: In vivo assessment of neurotransmitters and modulators with magnetic resonance spectroscopy: application to schizophrenia. Neurosci Biobehav Rev 2015;51:276-295.

31 Brandt AS, Unschuld PG, Pradhan S, Lim IA, Churchill G, Harris AD, Hua J, Barker PB, Ross CA, van Zijl PC, Edden RA, Margolis RL: Age-related changes in anterior cingulate cortex glutamate in schizophrenia: a ${ }^{1} \mathrm{H}$ MRS study at 7 tesla. Schizophr Res 2016;172:101105.
32 Rowland LM, Pradhan S, Korenic S, Wijtenburg SA, Hong LE, Edden RA, Barker PB: Elevated brain lactate in schizophrenia: a $7 \mathrm{~T}$ magnetic resonance spectroscopy study. Transl Psychiatry 2016;6:e967.

33 Taylor R, Neufeld RW, Schäfer B, Densmore M, Rajakumar N, Osuch EA, Williamson PC, Théberge J: Functional magnetic resonance spectroscopy of glutamate in schizophrenia and major depressive disorder: anterior cingulate activity during a color-word Stroop task. NPJ Schizophr 2015;1:15028.

34 Thakkar KN, Rösler L, Wijnen JP, Boer VO, Klomp DW, Cahn W, Kahn RS, Neggers SF: 7T proton magnetic resonance spectroscopy of gamma-aminobutyric acid, glutamate, and glutamine reveals altered concentrations in patients with schizophrenia and healthy siblings. Biol Psychiatry 2017;81:525-535.

-35 Matsuzawa D, Obata T, Shirayama Y, Nonaka H, Kanazawa Y, Yoshitome E, Takanashi J, Matsuda T, Shimizu E, Ikehira H, Iyo M, Hashimoto K: Negative correlation between brain glutathione level and negative symptoms in schizophrenia: a $3 \mathrm{~T}{ }^{1} \mathrm{H}$-MRS study. PLoS One 2008;3:e1944.

36 Terpstra M, Vaughan TJ, Ugurbil K, Lim KO, Schulz SC, Gruetter R: Validation of glutathione quantitation from STEAM spectra against edited ${ }^{1} \mathrm{H}$ NMR spectroscopy at 4T: application to schizophrenia. MAGMA 2005; 18 : 276-282.

37 Dash PK, Zhao J, Orsi SA, Zhang M, Moore AN: Sulforaphane improves cognitive function administered following traumatic brain injury. Neurosci Lett 2009;460:103-107.

38 Benedict AL, Mountney A, Hurtado A, Bryan KE, Schnaar RL, Dinkova-Kostova AT, Talalay P: Neuroprotective effects of sulforaphane after contusive spinal cord injury. J Neurotrauma 2012;29:2576-2586.

39 Cardozo LF, Pedruzzi LM, Stenvinkel P, Stockler-Pinto MB, Daleprane JB, Leite M Jr, Mafra D: Nutritional strategies to modulate inflammation and oxidative stress pathways via activation of the master antioxidant switch Nrf2. Biochimie 2013;95:1525-1533.

40 Keum YS: Regulation of the Keap1/Nrf2 system by chemopreventive sulforaphane: implications of posttranslational modifications. Ann NY Acad Sci 2011;1229:184-189.

41 Fahey JW, Talalay P: Antioxidant functions of sulforaphane: a potent inducer of phase II detoxication enzymes. Food Chem Toxicol 1999;37:973-979.

42 Park JH, Kim JW, Lee CM, Kim YD, Chung SW, Jung ID, Noh KT, Park JW, Heo DR, Shin YK, Seo JK, Park YM: Sulforaphane inhibits the Th2 immune response in ovalbumininduced asthma. BMB Rep 2012;45:311-316.

43 Brown RH, Reynolds C, Brooker A, Talalay P, Fahey JW: Sulforaphane improves the bronchoprotective response in asthmatics through Nrf2-mediated gene pathways. Respir Res 2015;16:106. 
-44 Dinkova-Kostova AT, Fahey JW, Kostov RV, Kensler TW: KEAP1 and done? Targeting the NRF2 pathway with sulforaphane. Trends Food Sci Technol 2017;69(pt B):257-269.

45 Singh K, Connors SL, Macklin EA, Smith KD, Fahey JW, Talalay P, Zimmerman AW: Sulforaphane treatment of autism spectrum disorder (ASD). Proc Natl Acad Sci USA 2014; 111:15550-15555.

46 Shiina A, Kanahara N, Sasaki T, Oda Y, Hashimoto T, Hasegawa T, Yoshida T, Iyo M, Hashimoto K: An open study of sulforaphane-rich broccoli sprout extract in patients with schizophrenia. Clin Psychopharmacol Neurosci 2015;13:62-67.

-47 Liu H, Talalay P, Fahey JW: Biomarker-guided strategy for treatment of autism spectrum disorder (ASD). CNS Neurol Disord Drug Targets 2016;15:602-613.

48 Aoyama K, Suh SW, Hamby AM, Liu J, Chan WY, Chen Y, Swanson RA: Neuronal glutathione deficiency and age-dependent neurodegeneration in the EAAC1 deficient mouse. Nat Neurosci 2006;9:119-126.

-49 Pinto RE, Bartley W: The effect of age and sex on glutathione reductase and glutathione peroxidase activities and on aerobic glutathione oxidation in rat liver homogenates. Biochem J 1969;112:109-115.

50 Wang H, Liu H, Liu RM: Gender difference in glutathione metabolism during aging in mice. Exp Gerontol 2003;38:507-517.

51 James D, Devaraj S, Bellur P, Lakkanna S, Vicini J, Boddupalli S: Novel concepts of broccoli sulforaphanes and disease: induction of phase II antioxidant and detoxification enzymes by enhanced-glucoraphanin broccoli. Nutr Rev 2012;70:654-665.

52 Kensler TW, Egner PA, Agyeman AS, Visvanathan K, Groopman JD, Chen JG, Chen TY, Fahey JW, Talalay P: Keap1-Nrf2 signaling: a target for cancer prevention by sulforaphane; in Pezzuto JM, Suh N (eds): Natural Products in Cancer Prevention and Therapy. Heidelberg/Berlin, Springer, 2013, vol 329, pp 163177.

-53 Egner PA, Chen JG, Wang JB, Wu Y, Sun Y, Lu JH, Zhu J, Zhang YH, Chen YS, Friesen MD, Jacobson LP, Muñoz A, Ng D, Qian GS, Zhu YR, Chen TY, Botting NP, Zhang Q, Fahey JW, Talalay P, Groopman JD, Kensler TW: Bioavailability of sulforaphane from two broccoli sprout beverages: results of a shortterm, cross-over clinical trial in Qidong, China. Cancer Prev Res (Phila) 2011;4:384-395.

54 Egner PA, Chen JG, Zarth AT, Ng D, Wang J, Kensler KH, Jacobson LP, Muñoz A, Johnson JL, Groopman JD, Fahey JW, Talalay P, Zhu J, Chen T-Y, Qian G-S, Carmella SG, Hecht SS, Kensler TW: Rapid and sustainable detoxication of airborne pollutants by broccoli sprout beverage: results of a randomized clinical trial in China. Cancer Prev Res (Phila) 2014;7:813-823.
55 Kensler TW, Chen J-G, Egner PA, Fahey JW, Jacobson LP, Stephenson KK, Ye L, Coady JL, Wang J-B, Wu Y, Sun Y, Zhang Q-N, Zhang B-C, Zhu Y-R, Qian G-S, Carmella SG, Hecht SS, Benning L, Gange SJ, Groopman JD, Talalay P: Effects of glucosinolate-rich broccoli sprouts on urinary levels of aflatoxin-DNA adducts and phenanthrene tetraols in a randomized clinical trial in He Zuo Township, Qidong, People's Republic of China. Cancer Epidemiol Biomarkers Prev 2005;14(pt 1): 2605-2613.

56 Kensler TW, Ng D, Carmella SG, Chen M, Jacobson LP, Muñoz A, Egner PA, Chen JG, Qian GS, Chen TY, Fahey JW, Talalay P, Groopman JD, Yuan J-M, Hecht SS: Modulation of the metabolism of airborne pollutants by glucoraphanin-rich and sulforaphane-rich broccoli sprout beverages in Qidong, China. Carcinogenesis 2012;33:101-107.

57 Shapiro TA, Fahey JW, Dinkova-Kostova AT, Holtzclaw WD, Stephenson KK, Wade KL, Ye L, Talalay P: Safety, tolerance, and metabolism of broccoli sprout glucosinolates and isothiocyanates: a clinical phase I study. Nutr Cancer 2006;55:53-62.

58 Fahey JW, Holtzclaw WD, Wehage SL, Wade KL, Stephenson KK, Talalay P: Sulforaphane bioavailability from glucoraphanin-rich broccoli: control by active endogenous myrosinase. PLoS One 2015; 10:e0140963.

59 Riedl MA, Saxon A, Diaz-Sanchez D: Oral sulforaphane increases phase II antioxidant enzymes in the human upper airway. Clin Immunol 2009;130:244-251.

60 Ye L, Dinkova-Kostova AT, Wade KL, Zhang Y, Shapiro TA, Talalay P: Quantitative determination of dithiocarbamates in human plasma, serum, erythrocytes and urine: pharmacokinetics of broccoli sprout isothiocyanates in humans. Clin Chim Acta 2002;316:43-53.

61 van Lieshout EM, Peters WH: Age and gender dependent levels of glutathione and glutathione S-transferases in human lymphocytes. Carcinogenesis 1998;19:1873-1875.

-62 Carnevale R, Sciarretta S, Violi F, Nocella C, Loffredo L, Perri L, Peruzzi M, Marullo AGM, De Falco E, Chimenti I, Valenti V, BiondiZoccai G, Frati G: Acute impact of tobacco versus electronic cigarette smoking on oxidative stress and vascular function. Chest 2016; 150:606-612.

63 Ellegaard PK, Poulsen HE: Tobacco smoking and oxidative stress to DNA: a meta-analysis of studies using chromatographic and immunological methods. Scand J Clin Lab Invest 2016;76:151-158.

64 Tietze F: Enzymic method for quantitative determination of nanogram amounts of total and oxidized glutathione: applications to mammalian blood and other tissues. Anal Biochem 1969;27:502-522.

-65 Sedlak TW, Saleh M, Higginson DS, Paul BD, Juluri KR, Snyder SH: Bilirubin and glutathione have complementary antioxidant and cytoprotective roles. Proc Natl Acad Sci USA 2009; 106:5171-5176.
66 Koga M, Serritella AV, Messmer MM, Hayashi-Takagi A, Hester LD, Snyder SH, Sawa A, Sedlak TW: Glutathione is a physiologic reservoir of neuronal glutamate. Biochem Biophys Res Commun 2011;409:596-602.

67 Tkáč I, Starčuk Z, Choi I-Y, Gruetter R: In vivo ${ }^{1} \mathrm{H}$ NMR spectroscopy of rat brain at 1 ms echo time. Magn Reson Med 1999;41:649_ 656.

68 Provencher SW: Estimation of metabolite concentrations from localized in vivo proton NMR spectra. Magn Reson Med 1993;30: 672-679.

69 Soher B, Semanchuk P, Todd D, Steinberg J, Young K: VeSPA: integrated applications for RF pulse design, spectral simulation and MRS data analysis. Proc Int Soc Mag Reson Med 19, 2011, p 1410.

70 Marenco S, Stein JL, Savostyanova AA, Sambataro F, Tan HY, Goldman AL, Verchinski BA, Barnett AS, Dickinson D, Apud JA, Callicott $\mathrm{JH}$, Meyer-Lindenberg A, Weinberger DR: Investigation of anatomical thalamocortical connectivity and FMRI activation in schizophrenia. Neuropsychopharmacology 2012;37:499-507.

71 Takayanagi M, Wentz J, Takayanagi Y, Schretlen DJ, Ceyhan E, Wang L, Suzuki M, Sawa A, Barta PE, Ratnanather JT, Cascella NG: Reduced anterior cingulate gray matter volume and thickness in subjects with deficit schizophrenia. Schizophr Res 2013;150:484490.

72 Cui LB, Liu J, Wang LX, Li C, Xi YB, Guo F, Wang HN, Zhang LC, Liu WM, He H, Tian P, Yin $\mathrm{H}, \mathrm{Lu} \mathrm{H}$ : Anterior cingulate cortex-related connectivity in first-episode schizophrenia: a spectral dynamic causal modeling study with functional magnetic resonance imaging. Front Hum Neurosci 2015;9:589.

73 Seeman P: Schizophrenia thalamus imaging: low benzamide binding to dopamine D2 receptors suggests fewer D2Short receptors and fewer presynaptic terminals. Psychiatry Res 2013;214:175-180.

74 Pergola G, Selvaggi P, Trizio S, Bertolino A, Blasi G: The role of the thalamus in schizophrenia from a neuroimaging perspective. Neurosci Biobehav Rev 2015;54:57-75.

75 Reid MA, Stoeckel LE, White DM, Avsar KB, Bolding MS, Akella NS, Knowlton RC, den Hollander JA, Lahti AC: Assessments of function and biochemistry of the anterior cingulate cortex in schizophrenia. Biol Psychiatry 2010;68:625-633.

76 Kraguljac NV, White DM, Hadley J, Reid MA, Lahti AC: Hippocampal-parietal dysconnectivity and glutamate abnormalities in unmedicated patients with schizophrenia. Hippocampus 2014;24:1524-1532.
Sulforaphane Augments Glutathione and Influences Brain Metabolites
Mol Neuropsychiatry 2017;3:214-222 DOI: $10.1159 / 000487639$ 
-77 Knöchel C, Stäblein M, Storchak H, Reinke B, Jurcoane A, Prvulovic D, Linden DE, van de Ven V, Ghinea D, Wenzler S, Alves G, Matura S, Kröger A, Oertel-Knöchel V: Multimodal assessments of the hippocampal formation in schizophrenia and bipolar disorder: evidences from neurobehavioral measures and functional and structural MRI. Neuroimage Clin 2014;6:134-144.

78 Xin L, Mekle R, Fournier M, Baumann PS, Ferrari C, Alameda L, Jenni R, Lu H, Schaller B, Cuenod M, Conus P, Gruetter R, Do KQ: Genetic polymorphism associated prefrontal glutathione and its coupling with brain glutamate and peripheral redox status in early psychosis. Schizophr Bull 2016;42:1185-1196.
79 Tanaka TCJ, Marsman A, Wang H, Bonekamp S, Kim PK, Higgs C, Posporelis S, Varvaris M, Edden RAE, Pomper M, Schretlen D, Cascella N, Barker PB, Sawa A: Blood glutathione predicts cortical glutamate levels and cognitive function. Society for Neuroscience Annual Meeting, November 18, 2014, Washington.

80 Bahadoran Z, Mirmiran P, Hosseinpanah F, Hedayati M, Hosseinpour-Niazi S, Azizi $F$ : Broccoli sprouts reduce oxidative stress in type 2 diabetes: a randomized double-blind clinical trial. Eur J Clin Nutr 2011;65:972977.
81 Emiliani FE, Sedlak TW, Sawa A: Oxidative stress and schizophrenia: recent breakthroughs from an old story. Curr Opin Psychiatry 2014;27:185-190.

82 Zhao J, Kobori N, Aronowski J, Dash PK: Sulforaphane reduces infarct volume following focal cerebral ischemia in rodents. Neurosci Lett 2006;393:108-112.

83 Shirai Y, Fujita Y, Hashimoto K: Effects of the antioxidant sulforaphane on hyperlocomotion and prepulse inhibition deficits in mice after phencyclidine administration. Clin Psychopharmacol Neurosci 2012;10:94-98. 